\title{
Is depression a chronic mental illness?
}

\author{
S. M. Monroe ${ }^{1 *}$ and K. L. Harkness ${ }^{2}$ \\ ${ }^{1}$ Department of Psychology, University of Notre Dame, Notre Dame, IN, USA \\ ${ }^{2}$ Department of Psychology, Queens University, Kingston, ON, Canada
}

\begin{abstract}
Over the past few decades, theory and research on depression have increasingly focused on the recurrent and chronic nature of the disorder. These recurrent and chronic forms of depression are extremely important to study, as they may account for the bulk of the burden associated with the disorder. Paradoxically, however, research focusing on depression as a recurrent condition has generally failed to reveal any useful early indicators of risk for recurrence. We suggest that this present impasse is due to the lack of recognition that depression can also be an acute, timelimited condition. We argue that individuals with acute, single lifetime episodes of depression have been systematically eclipsed from the research agenda, thereby effectively preventing the discovery of factors that may predict who, after experiencing a first lifetime episode of depression, goes on to have a recurrent or chronic clinical course. Greater awareness of the high prevalence of people with a single lifetime episode of depression, and the development of research designs that identify these individuals and allow comparisons with those who have recurrent forms of the disorder, could yield substantial gains in understanding the lifetime pathology of this devastating mental illness.
\end{abstract}

Received 15 July 2011; Revised 18 August 2011; Accepted 22 August 2011; First published online 14 October 2011

Key words: Chronicity, depression, recurrence, relapse.

Perspectives on depression have evolved over recent decades from conceptualizing the disorder as primarily an acute, time-limited psychiatric condition to a recurrent and chronic life-long disease (Zis \& Goodwin, 1979; Belsher \& Costello, 1988). Today, depression is typically characterized as a 'highly recurrent illness' (Solomon et al. 2000, p. 229) or as a 'highly recurrent disorder' (Burcusa \& Iacono, 2007, p. 959). Little doubt exists that depression can be a severely disabling problem that recurs repeatedly over the life course, thereby representing a chronic illness for many. But is depression always so enduring? Can depression be acute and time-limited? Our answers to these questions point clearly to a missing ingredient in the research literature that, if recognized, could revitalize future studies on recurrence in depression. $\dagger$

The case for depression's chronicity is compelling. According to present estimates, approximately $60 \%$ of people who develop a first lifetime episode of major depressive disorder (MDD) will incur a second episode, $70 \%$ of those with a second MDD episode will suffer a third, and $90 \%$ of those with three or more

* Address for correspondence: Professor S. M. Monroe, University of Notre Dame, Notre Dame, IN, USA.

(Email : smonroe1@nd.edu) [S. M. Monroe]

(Email: harkness@queensu.ca) [K. L. Harkness]

$\dagger$ The present article selectively emphasizes key issues and conclusions drawn from a more comprehensive recent conceptual analysis of recurrence in major depression (see Monroe \& Harkness, 2011). episodes will experience further, often many more, recurrences (APA, 2000; Solomon et al. 2000). Statistics such as these, promulgated widely throughout the field and embodied in DSM-IV-TR (APA, 2000), have convinced many that depression is a life-long psychiatric disease, one that requires ongoing monitoring and treatment (Andrews, 2001; Keller, 2003).

The crucial question, though, is whether or not these descriptive statistics map onto the lifetime course of depression with pointillistic fidelity, or are there broad brush strokes at work that mask crucial pieces of the empirical picture? The answer is that depression is not always a chronic psychiatric disease, and not even nearly always so.

The widely disseminated estimates on recurrence alone speak directly to this fact. The statistics quoted above are based largely on studies from the landmark Collaborative Depression Study (CDS), which suggests that roughly $40 \%$ of individuals with a first episode of depression do not suffer another one (Mueller et al. 1999; Solomon et al. 2000). This represents a very significant proportion of the population of depressed persons. Yet even these under-recognized corollary data are based upon a very severely depressed sample (e.g. almost $75 \%$ were in-patients, $90 \%$ probable or definite endogenous subtype; Solomon et al. 2000), and are subject to biases that almost without question inflate these recurrence estimates (e.g. Berkson bias, the 'clinician's illusion'; Berkson, 1946; Cohen \& Cohen, 1984). More recently, a report drawn from the 
Baltimore site of the Epidemiologic Catchment Area (ECA) Study culled out 92 cases with a first lifetime onset of MDD occurring over a minimum follow-up period of 13 years (Eaton et al. 2008). This latter investigation, using a population-based sample, provides an important counterpart to other studies on the lifetime course of depression. Significantly, Eaton et al. (2008) found that approximately $50 \%$ of firstonset cases recovered and did not experience another episode (even up to a maximum follow-up period of 23 years). (For similar or greater estimates of the proportion of initially depressed cases that do not recur, see Mattisson et al. 2007; Moffitt et al. 2010.)

Experts can quibble about the exact numbers, but the undeniable point is that many incident cases of depression, perhaps half or more, recover and remain depression free. This is an important matter for clinical and public health considerations, and it is an extremely significant finding for theory and research. These statistics highlight a basic paradox: depression can be both an acute, time-limited condition and a chronic, life-long condition. A pivotal question concerns what distinguishes individuals who incur a first lifetime episode and never experience another episode of depression from those who experience recurrences. What predicts, early on, who will and will not later recur?

Surprisingly little is known (see Monroe \& Harkness, 2011). Most studies lament the fact that so few useful predictors of recurrence have been discovered (e.g. Mueller et al. 1999; Hollon et al. 2006; Eaton et al. 2008). But here we must pause and consider how this could possibly be so. Surely there must be some indicators that can be prognostically useful? We suggest that in the sincere quest to document depression's recurrent and chronic course, important information has been overlooked that could help to eliminate this predictive impasse. In particular, the vast research literature on depression and its recurrences rarely, if ever, attends in a systematic manner to individuals who suffer a first lifetime episode of depression and never become depressed again - nonrecurrences. As we have pointed out, these people constitute approximately one-half of the population of depressed persons and represent the most important and promising group for future study. Yet they have been essentially ignored.

This general omission from research of those with a single lifetime episode of depression is so complete that it is difficult for most researchers and clinicians to recognize it. Take, for example, the vast crosssectional research literature on depressed patients who have experienced varying numbers of past depressive episodes. Time and time again such work has been undertaken in the hope of discovering what distinguishes people with one, two, three, or more prior episodes of the disorder. Although much has been learned in the process, collectively these efforts have yielded a paucity of predictors for recurrence (e.g. Mueller et al. 1999; Hollon et al. 2006; Eaton et al. 2008). But perhaps these research designs are doomed to failure because they cannot directly address the scientific question at hand. Technically speaking, all that these cross-sectional studies can do is inform us about how people with differing histories of prior depression presently differ in their current episode along demographic, clinical or theoretical lines. These types of studies provide no direct information about people who, having recovered from an episode of depression, never recur again (Monroe \& Harkness, 2011).

Research comparing individuals in a first episode of depression to those with one or more recurrences at first blush seems to provide a more appropriate method for establishing predictors of recurrence. But here, too, the design is seriously compromised. Specifically, these studies provide no information regarding which of these first-episode patients never suffer another episode and which go on to additional recurrences. As indicated above, approximately half of people in a first lifetime episode of depression will eventually convert and become people with two or more episodes. Consequently, over time, the firstepisode group will divide into two groups: those who never again recur and those who do. As a result of this unforeseen future, comparisons of a first-episode group with individuals possessing greater histories of recurrence will be insensitive for detecting pre- or peri-morbid risk indicators (as only half are believed to be 'true' non-recurrences). Yet the findings for predictors of recurrence (or lack thereof) in these cross-sectional studies typically are not discussed in the context of this major design limitation. Without the availability of non-recurrences for direct comparisons with recurrences, it becomes less surprising that few robust predictors of recurrence have been discovered to date (Monroe \& Harkness, 2011).

The skeptic might counter these contentions and point to the many fine longitudinal studies of depression's recurrence that have been undertaken. We maintain that although these longitudinal studies have enriched our understanding of many issues, they have not addressed the central question at hand in any systematic manner: that of understanding which incident cases of depression will and will not recur. For example, longitudinal investigations have often done a fine job of predicting who suffers a recurrence following remission of an index episode (e.g. prior recurrences predict future recurrences; Mueller et al. 1999). There have also been some excellent longitudinal 
studies evaluating differential predictors for firstonset cases of depression compared to recurrences of the disorder (e.g. Lewinsohn et al. 1999; Alloy et al. 2006). However, evaluating differential predictors for first-onset cases relative to recurrences is a very different research question from evaluating differential predictors of who, once initially depressed, will and will not recur.

There do exist a very small number of longitudinal studies that follow cases with a first depressive episode for a sufficient time to examine predictors of recurrence. However, these studies have been limited to specific predictors (e.g. onset age, Bland et al. 1986; sex differences, Simpson et al. 1997) or have not had prediction of recurrence as a central goal (Eaton et al. 2008). We urge the reader to scrutinize the literature with an eye specifically on this question: Who, of the initially depressed, recurs and who does not? To our knowledge, very few studies come even close, and none has investigated a broad array of demographic, clinical and theoretical predictors on a sufficiently large sample followed for a reasonable duration of time. Once again, the lack of predictors of recurrence now seems less surprising, and it is becoming increasingly obvious as to why it might be so.

The persistent skeptic may counter once more, this time with an apparent coup de grace: past history of depression has been found consistently to be a robust predictor of future recurrences (e.g. Solomon et al. 2000; Hollon et al. 2006). We do not disagree. But this is of no help in forecasting the clinical course for the first lifetime incident cases. And it is precisely these individuals who, in all likelihood, will prove indispensable for understanding the indicators and origins of recurrence.

Who becomes depressed but once, and never again in her or his lifetime? How can someone who is depression-capable escape forever depression's return? Do these people remain vulnerable, but also somehow avoid the circumstances needed to translate the predisposition into depression? Do they somehow become less vulnerable, perhaps even resilient (Gut, 1989; Southwick et al. 2005; Andrews \& Thomson, 2009)? Do they lead relatively symptom-free productive lives, or are they beset by subsyndromal symptoms or other psychiatric conditions? As these single lifetime cases of depression have been overlooked, we know very little about them. But it seems highly likely that they differ in important ways from their recurrent counterparts prior to, or immediately following, their only depression.

Establishing predictors of recurrence following the first lifetime episode of depression could transform basic and clinical research and lead to breakthrough advances in understanding and preventing recurrences (Monroe \& Harkness, 2011). By examining recurrent-prone individuals prior to developing multiple episodes, early differences between those who go on to recurrences versus those who do not are likely to be of causal relevance (as opposed to being confounds or consequences of having experienced multiple episodes or treatment regimens for depression). It is likely that single lifetime episode and recurrent cases differ in many ways, ranging from genetic vulnerability, neuroendocrine profiles, developmental history, personality, current environmental factors and co-morbid psychiatric or general medical illnesses through such possible factors as nutrition, exercise and concurrent medications. Treatment research, too, could be altered dramatically for the better. For example, characterization of a high-risk recurrence group would allow for the development and empirical study of intervention and prevention procedures specifically designed to remediate established recurrence vulnerabilities. At the same time, characterization of a group that is not likely to suffer depression past the first episode would help in promoting the cost-effectiveness of treatment strategies by enabling clinicians to direct resources to the patients at highest risk. Research insights could also possibly 'feed backward' to inform theory about depression more generally, and ultimately perhaps inform prevention for the first onset of depression (Monroe \& Harkness, 2011).

Is depression a chronic mental illness, or is depression an acute psychological disorder? The question needs to be enlarged to face the inconvenient but inescapable fact that depression can be either, that depression as we currently conceive and define the condition is 'both'. The evidence is prima facie: approximately half of people who become depressed never do so again, and approximately half do (Eaton et al. 2008). In recognizing and resolving this seeming paradox, and by adding the acute depressive conditions that do not recur to the research agenda, early indices of recurrence risk may be found, and the trajectory of depression that is so chronic, severe and disabling eventually may be altered for the betterment of so very many.

\section{Declaration of Interest}

None.

\section{References}

Alloy LB, Abramson LY, Whitehouse WG, Hogan ME, Panzarella C, Rose DT (2006). Prospective incidence of first onsets and recurrences of depression in individuals at high and low cognitive risk for depression. Journal of Abnormal Psychology 115, 145-156. 
Andrews G (2001). Should depression be managed as a chronic disease? British Medical Journal 322, 419-421.

Andrews PW, Thomson JA (2009). The bright side of being blue: depression as an adaptation for analyzing complex problems. Psychological Review 116, 620-654.

APA (2000). Diagnostic and Statistical Manual of Mental Disorders, 4th edn, text revision (DSM-IV-TR).

American Psychiatric Association: Washington, DC.

Belsher G, Costello CG (1988). Relapse after recovery from unipolar depression: a critical review. Psychological Bulletin 104, 84-96.

Berkson J (1946). Limitations of the application of fourfold table analysis to hospital data. Biometrics 2, 47-53.

Bland RC, Newman SC, Orn H (1986). Recurrent and nonrecurrent depression. A family study. Archives of General Psychiatry 43, 1085-1089.

Burcusa SL, Iacono WG (2007). Risk for recurrence in depression. Clinical Psychology Review 27, 959-985.

Cohen P, Cohen J (1984). The clinician's illusion. Archives of General Psychiatry 41, 1178-1182.

Eaton WW, Shao H, Nestadt G, Lee HB, Bienvenu OJ, Zandi P (2008). Population-based study of first onset and chronicity in major depressive disorder. Archives of General Psychiatry 65, 513-520.

Gut E (1989). Productive and Unproductive Depression: Success or Failure of a Vital Process. Basic Books, Inc.: New York.

Hollon SD, Shelton RC, Wisniewski S, Warden D, Biggs MM, Friedman ES, Husain M, Kupfer DJ, Nierenberg AA, Petersen TJ, Shores-Wilson K, Rush AJ (2006). Presenting characteristics of depressed outpatients as a function of recurrence: preliminary findings from the STAR*D clinical trial. Journal of Psychiatric Research 40, 59-69.

Keller MB (2003). Past present, and future directions for defining optimal treatment outcome in depression: remission and beyond. Journal of the American Medical Association 289, 3152-3160.
Lewinsohn PM, Allen NB, Seeley JR, Gotlib IH (1999). First onset versus recurrence of depression: differential processes of psychosocial risk. Journal of Abnormal Psychology 108, 483-489.

Mattisson C, Bogren M, Horstmann V, Munk-Jörgensen P, Nettelbladt $P$ (2007). The long-term course of depressive disorders in the Lundby study. Psychological Medicine 37, 883-891.

Moffitt TE, Caspi A, Taylor A, Kokaua J, Milne BJ, Polanczyk G, Poulton R (2010). How common are common mental disorders? Evidence that lifetime prevalence rates are doubled by prospective versus retrospective ascertainment. Psychological Medicine 40, 899-909.

Monroe SM, Harkness KL (2011). Recurrence in major depression: a conceptual analysis. Psychological Review. Published online: 5 September 2011. doi:10.1037/ a0025190.

Mueller TI, Leon AC, Keller MB, Solomon DA, Endicott J, Coryell W, Warshaw M, Maser JD (1999). Recurrence after recovery from major depressive disorder during 15 years of observational follow-up. American Journal of Psychiatry 156, 1000-1006.

Simpson HB, Nee JC, Endicott J (1997). First-episode major depression: few sex differences in course. Archives of General Psychiatry 54, 633-639.

Solomon DA, Keller MB, Leon AC, Mueller TI, Lavori PW, Shea MT, Coryell W, Warshaw M, Turvey C, Maser JD, Endicott J (2000). Multiple recurrences of major depressive disorder. American Journal of Psychiatry 157, 229-233.

Southwick SM, Vythilingam M, Charney DS (2005). The psychobiology of depression and resilience to stress: implications for prevention and treatment. Annual Review of Clinical Psychology 1, 255-291.

Zis AP, Goodwin FK (1979). Major affective disorder as a recurrent illness: a critical review. Archives of General Psychiatry 36, 835-839. 